\title{
$O$ aspecto missionário das religiões na defesa da casa comum segundo a Laudato Si'
}

\author{
The missionary aspect of religions in the defense of the \\ common house according to Laudato Si'
}

Edevaldo Rocha

\section{Resumo}

A finalidade deste artigo é apresentar a grave crise ecológica que vivemos hoje, resultado de um comportamento humano tirânico, individualista e consequentemente dissociado da natureza que afeta e desequilibra todo meio ambiente, causa grande prejuízo à toda humanidade principalmente o aumento da pobreza e a injustiça social. Diante dessas adversidades o papel profético das religiões de denúncia da injustiça e anúncio de esperança visa superar o exclusivismo gerador de desiquilíbrio em todo planeta Terra. A práxis desse movimento profético tem como linha orientadora o diálogo, instrumento imprescindível de conscientização ambiental integradora. Esse propósito profético das religiões na defesa do ecossistema apresenta a correspondência tênue entre religião e ecologia, que a partir do encantamento da Criação, desabrocha a percepção e ação da humanidade da sua relação de alteridade com a natureza. Essa mudança de perspectiva pode superar a arrogância humana imbuída de um antropocentrismo que devasta todo meio ambiente. Esse apelo de conversão ecológica perpassa a encíclica Laudato Si' do Papa Francisco que conclama a todos no desafio de proteger a Casa Comum.

Palavras-chave: Missionaridade. Conversão ecológica. Ecoespiritualidade. Conscientização. 


\section{Abstract}

The purpose of this article is to present the serious ecological crisis that we live today, the result of a human behavior tyrannical, individualistic and consequently dissociated from the nature that affects and unbalances every environment, causes great harm to all humanity, especially the increase of poverty and social injustice. Faced with these adversities, the prophetic role of the religions denouncing injustice and proclaiming hope is to overcome all exclusivism that generates unbalance in all planet Earth. The praxis of this prophetic movement is guided by dialogue, an indispensable instrument of integrating environmental awareness. This prophetic purpose of religions in the defense of the ecosystem presents the tenuous correspondence between religion and ecology, which from the enchantment of Creation, unleashes mankind's perception and action of its relationship of alterity with nature. This change of perspective can overcome arrogance human being imbued with an anthropocentrism that devastates every environment. This appeal for ecological conversion runs through the encyclical Laudato Si' of Pope Francis who calls everyone in the challenge of protecting the Common House.

Keywords: Missionarity. Ecological conversion. Eco-spirituality. Awareness.

\section{Introdução}

O serviço ao Reino de Deus exige compromisso na construção de uma sociedade igualitária, justa e pacífica, postura que vai na contramão do mundo hodierno que vive tempos difíceis devido a uma mentalidade de progresso ilimitado que permite a exploração nociva da natureza e, consequentemente, afeta os mais pobres. Tudo isso em prol de um antropocentrismo imperioso. Diante desta adversidade emerge como desafio a preocupação com o meio ambiente pautada num processo de conscientização e responsabilidade comum na defesa da Criação.

No íntimo desta causa está o projeto divino, uma vez que ultrapassa barreiras e atinge as dimensões do Reino de Deus. Logo, o Reino é maior que qualquer instituição, independe de raça, cultura e tradições religiosas. Moverse a partir da inspiração do Reino de Deus está relacionado a uma postura que surge da compreensão do caráter sagrado da natureza, ação que produz no indivíduo uma visão holística e integrada de toda a Criação. É esta a 
responsabilidade da religião que a partir do projeto do Reino de Deus promove a desinstalação de seus redutos defensivos e a impulsiona ao compromisso compartilhado.

Em vista do projeto do Reino de Deus a encíclica Laudato Si 'é o grande apelo do Papa Francisco, na responsabilidade pela casa comum por intermédio da educação ambiental. Nesta encíclica o Bispo de Roma avista nas religiões o papel de re-ligar a criação ao seu Criador, o ser humano à natureza. Essa maneira de conceber o mundo não descarta uma mística encarnada e integrada: a ecoespiritualidade.

\section{O novo paradigma da atividade missionária}

O Concílio Vaticano II, ao seguir as pegadas do Papa João XXIII, no desejo de um aggiornamento, traçou linhas inovadoras e estabeleceu um novo paradigma na compreensão sobre a missão da Igreja, deixando para trás o velho modelo missionário proselitista e assumindo uma atitude de reconhece-la como parte da sociedade e familiarizando-se com suas tradições nacionais e religiosas, com base no fato que a semente do Verbo está presente ocultamente, exigindo uma presença animada pela caridade cuja a meta é a promoção da dignidade humana e a comunhão como fruto do projeto salvífico de Deus. ${ }^{1}$

Esta proposta conciliar da atividade missionária é assumida e corroborada pela Conferência Episcopal Latino-Americana e Caribenha de Aparecida, na qual afirma-se que a fé nos liberta do isolamento e nos conduz à comunhão, ${ }^{2}$ fonte essencial que atrai pela força do amor homens e mulheres que peregrinam por este mundo no anseio de darem sentido à sua existência. $\mathrm{Se}$ a fé não é isolamento, significa que há uma exigência na adesão a Jesus Cristo: a saída de si mesmo, da comodidade e do conforto para ir ao encontro do outro. Assumir essa proposta missionária significa superar as estruturas pós-modernas individualistas e injustas em prol da instauração de estruturas mais justas e fraternas conforme os critérios evangélicos. ${ }^{3}$

A Igreja dá um grande passo na evangelização ao ultrapassar a ideia missionária de apenas pregar as verdades reveladas quando assume o anúncio de um Deus que se revela na história para salvar a humanidade por meio do amor e da justiça. Trata-se de um novo impulso que favorece uma ação evangelizadora orientada para o diálogo, comunhão e saída.

\footnotetext{
${ }^{1}$ AG 11-12.

${ }^{2}$ DAp 156.

${ }^{3}$ DAp 210.
} 
O Papa Francisco entende a ação evangelizadora, como uma Igreja em saída, entretanto, esta saída não se resume na transmissão do evangelho a espaços geográficos com intenção de expansão e nem apenas ao desejo de impor a própria doutrina nos espaços secularizados da sociedade, mas estar em saída requer mudança de mentalidade, ou seja, uma conversão pastoral. ${ }^{4} \mathrm{~A}$ partir deste pressuposto o discípulo missionário é aquele que toma a iniciativa, porque entende que Jesus também o fez por amor, indo ao encontro dos mais fragilizados. Portanto, uma Igreja em saída requer ousadia, paciência, esvaziamento para fazer multiplicar os frutos da salvação - libertação das estruturas injustas da pós-modernidade na criação de estruturas mais justas e fraternas. Todas essas ações sempre imbuídas de grande alegria são o cerne da mensagem evangélica. ${ }^{5}$

\section{A missão das religiões em frente à tecnocracia e ao antropocentrismo, sintomas da crise ecológica}

A missionaridade por ter como princípio o movimento de saída em vista da comunhão através do diálogo, não prescinde de um agir permanente de respeito, compreensão e escuta mútua. Pode-se considerar um novo espírito solidário, capaz de aproximar duas culturas ou tradições religiosas diferentes que a partir de tarefas comuns tal como a justiça e a paz, podem se reconhecer sem deixar de lado a própria experiência, identidade e tradição.

É nesta perspectiva do diálogo que o Papa Francisco faz, por meio da Laudato $\mathrm{Si}$ ', um apelo a todas as pessoas e lança como desafio a busca de soluções para a crise ambiental, ${ }^{6}$ tendo como referência a realidade histórica e não apenas uma simples ideia. Esta conduta do Papa não o distancia da espiritualidade, pelo contrário, Prates, ao traçar as linhas de reflexão teológica do Papa Francisco na elaboração da Laudato Si', ressalta que a metodologia utilizada é a da espiritualidade como proposta de edificação da ecologia integral cujo o enunciado básico é o da realidade que sobressai sobre a ideia. ${ }^{7}$

A iniciativa do Papa Francisco na Laudato Si' sobre questões que afetam a casa comum, fruto de uma leitura da realidade, adquire grande importância porque seu interesse pretende despertar a consciência individual e comunitária sobre os graves problemas que degradam o meio ambiente, tal compreensão

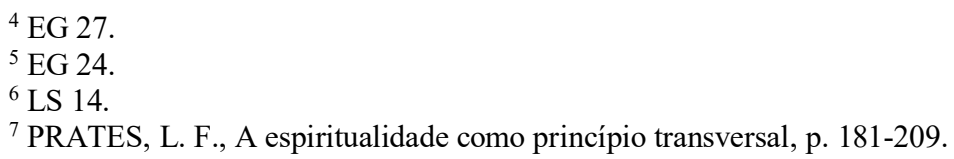


tem como enfoque a relação de interdependência entre o ser humano e a natureza que produz uma condição de vida melhor para a geração presente e futura.

O Papa Francisco, ao elencar os problemas ambientais - tais como: poluição, aquecimento do sistema climático, escassez d'agua, perda da biodiversidade - afirma que estes sintomas da crise ecológica estão ligados à raiz humana que, pautada pela tecnocracia e no antropocentrismo, afetam toda vida social humana, principalmente os mais pobres. ${ }^{8}$

Referente à tecnocracia, Leonardo Boff acrescenta que esta matriz humana de desenvolvimento social e ambiental torna-se equívoca quando as instituições políticas e econômicas querem assumir uma proposta ecológica de diminuição da miséria com a aceleração do desenvolvimento a fim de obter equilíbrio ecológico. Segundo essa lógica, quanto menos pobreza, menos poluição. Isto não passa de um mascaramento do desenvolvimento sustentável que atende interesses do lucro, por isso, ao invés de se chamar desenvolvimento deveria ser conhecido apenas como crescimento material. ${ }^{9}$ O Papa enfatiza que este modo de assumir o desenvolvimento sustentável que está na moda hoje em dia, no qual grandes corporações industriais e estatais, órgãos políticos e econômicos entendem o discurso verde, não passa de uma postura simplesmente orientada para o lucro sem uma preocupação real com a proposta ambiental, isso ocorre devido ao fato de estarem distantes da degradação humana e social que afeta particularmente os excluídos, ${ }^{10}$ portanto, a tecnocracia está a serviço do poder e não do desenvolvimento humano.

$\mathrm{O}$ antropocentrismo mencionado pelo Papa Francisco está vinculado a uma visão humana de domínio sobre a criação, ferindo o aspecto fundamental da sua existência que é a relação, ou seja, a sua interligação com toda natureza e todos os seres. ${ }^{11}$ Murad interpreta essa perda de vínculo com a natureza como desejo do ser humano de assenhoramento sobre ela:

O ser humano se assenhorou do planeta. Considera-se seu patrão. Perdeu o vínculo com as criaturas e as toma como "recursos" ou "coisas". Baseado na ciência, na tecnologia e no espírito conquistador do mercado global, considera-se dono absoluto. Sonha com um futuro promissor. $\mathrm{Na}$

\footnotetext{
${ }^{8}$ LS 20-42; 102; 115.

${ }^{9}$ BOFF, L., Ecologia grito da terra, grito dos pobres, p. 106-107.

${ }^{10}$ LS 49-50

${ }^{11}$ LS 117.
} 
realidade, construiu um modelo insustentável, que gera crescente exclusão social e enfraquecimento do ecossistema. ${ }^{12}$

Paulo Suess associa esse antropocentrismo desordenado ao esquecimento humano de suas raízes antropológicas:

O distanciamento produziu, na consciência e na imaginação, uma ruptura com a natureza que na realidade não aconteceu. A humanidade não quer ser lembrada dos seus ancestrais nem de sua animalidade ou naturalidade. Rompeu progressivamente, no seu imaginário, a conexão que permitiu compreender o ser humano como parte integrante da natureza. A partir desse momento a relação natureza humana e cultura humana tornou-se caracterizada pela dominação e exploração e em prejuízo não só da natureza "objetiva", mas também da natureza "subjetiva" que sobrevive em cada ser humano. ${ }^{13}$

Sem dúvida, o tempo vigente está marcado pela falta de consciência ecológica, isso indica que deve haver assimilação e uma releitura do contexto atual para reelaborar o destino do planeta acentuando práticas transformadoras capazes de despertar uma percepção ética na busca de um novo paradigma civilizacional de organização da sociedade orientada para a integralidade das relações humanas. ${ }^{14}$

É neste contexto que as religiões devem assumir a missão de serem luzes que permitam iluminar as penumbras que permeiam o planeta Terra por meio da tomada de uma consciência ecológica, ${ }^{15}$ proporcionando para humanidade um estilo de vida em harmonia com a natureza sem colocar em risco o futuro das próximas gerações.

O apelo do Papa Francisco para tomada de consciência sobre a questão ecológica envolve uma solidariedade global cujo o papel das religiões é fundamental. Segundo Sanchez, está subtendido em toda Laudato Si', o desafio das religiões de enfrentarem por meio de um processo dialogal e fraterno a construção de uma nova aliança entre a humanidade e a natureza. ${ }^{16}$

\footnotetext{
${ }^{12}$ MURAD, A., Ecologia, consciência planetária e bem viver, p. 17-61.

${ }^{13}$ SUESS, P., Introdução à teologia da missão, p. 179.

${ }^{14}$ MURAD, A., Ecologia, consciência planetária e bem viver, p. 17-61.

${ }^{15}$ FRANKY, C. H. D.; AGUIRRE, A. C., Espiritualidades, religiões e ecologia, p. 103-135.

${ }^{16}$ SANCHEZ, W. L., O diálogo inter-religioso, p. 157-178.
} 


\section{As religiões no processo de re-ligação entre o ser humano e a natureza}

O contexto atual está marcado pela exploração massiva da natureza com uma falsa ideia de corrida de desenvolvimento. Esse tipo de mentalidade produz hábitos pautados no consumo e empurra o planeta para a escassez de recursos naturais pondo em risco tanto as presentes gerações quanto as futuras. É dentro desta perspectiva que o Papa Francisco vê nas religiões o lugar em que pode efetuar-se a conscientização ecológica em que se permita o enfrentamento dos graves problemas ambientais. Esta questão ecológica pode ser construída entre as religiões num processo de diálogo entre elas a partir de cuidar da natureza, da defesa dos pobres e da construção de um mundo fraternal. Esta seria a causa comum que as uniria. ${ }^{17}$

É necessário ser consciente de que o chamado para o cuidado com a natureza é universal, ninguém deve estar isento desta iniciativa, porém, as religiões adquirem papel de protagonismo nessa empreitada. Essa posição das religiões é muito clara para o Papa Francisco, que entende essa atitude não apenas como da Igreja Católica Apostólica Romana. Isso é demonstrado na Laudato Si' quando cita o Patriarca Bartolomeu num discurso em Santa Bárbara Califórnia em 1997 onde enfatiza toda ação de destruição da natureza como pecado contra Deus. ${ }^{18}$

Diaz Franky e Cáceres Aguirre, ao falarem sobre a responsabilidade ambiental das religiões, destacam as diversas iniciativas, particularmente fóruns e debates, sem prescindirem da espiritualidade, mas conectadas à realidade no compromisso de se unirem para produzir uma ética global com interesse de harmonizar a relação da humanidade com a natureza. Desses eventos religiosos, sobressaem as contribuições do "Parlamento das Religiões do Mundo, do Fórum sobre as Religiões e Ecologia da Universidade de Yale, da Aliança de Religiões e Conservação (ARC), da Aliança das Civilizações (ONU), da Mesa Ecoteológica Inter-Religiosa de Bogotá". ${ }^{19}$

Diante da crise ecológica que afeta gravemente o planeta Terra, tornando-o cada vez mais combalido, comprometendo de forma irreversível a vida de todos os seres vivos, Leonardo Boff eleva a religião ao patamar de revolucionária, sendo ela, capaz de propor uma mudança estrutural de mentalidade, abandonando as estruturas cosmológicas de dominação, ou seja,

\footnotetext{
${ }^{17}$ LS 199-201.

${ }^{18}$ LS 8.

${ }^{19}$ Com relação aos eventos religiosos citados há uma descrição resumida de cada um deles em: FRANKY, C. H. D.; AGUIRRE, A. C., Espiritualidades, religiões e ecologia, p. 103-135.
} 
assumindo uma linguagem de integração e interação, estabelecendo um nó de relações e re-ligações, ${ }^{20}$ portanto, as religiões realmente possuem em sua gênese mais profunda o caráter missionário de re-ligar.

Partindo do pressuposto de que, no decorrer da história, o ser humano rompeu o laço com a natureza em virtude de uma percepção mais materialista, afastando-o também da realidade transcendente parte de sua integralidade, a responsabilidade das tradições religiosas passam a ter em comum a aproximação, ou melhor, a re-ligação da matéria e do espírito, pois, se no passado primitivo as experiências religiosas estavam fincadas na experiência no encantamento da criação, significando uma visão integralista do mundo. Hoje as religiões adquirem uma maior relevância na solução da crise ecológica por serem capazes de retomar aquilo que tiveram como experiência religiosa na sua origem que foi o encantamento do universo ao qual se achavam conectadas, ligadas, unidas e habitantes de uma casa comum, isso pode ser configurado como espiritualidade.

A partir desse horizonte, Murad certifica que as tradições religiosas primitivas sempre tiveram como lugar de espaço sagrado a espiritualidade dedicada à Mãe Terra. $\mathrm{O}$ processo de evolução espiritual incluía as dimensões de respeito à Mãe Natureza. Neste contexto em que a transcendência de Deus se encontra com a imanência divina na Criação, deve servir de estímulo a todas as religiões na busca de uma causa ecológica, como fonte de enriquecimento da espiritualidade, sendo o mundo a casa comum, lugar de fortalecimento de uma mística encarnada e integradora. ${ }^{21}$

No contexto atual de pluralidade religiosa, em que os desafios caminham na busca de uma efetivação do diálogo inter-religioso, desinstalando as religiões de sua zona de conforto, a ecologia traz consigo uma tarefa comum de comprometimento das religiões com ela e a espiritualidade que se traduz numa visão unificadora, sem oposição entre matéria e espírito, esta perspectiva integradora é denominada ecoespiritualidade ou espiritualidade ecológica. ${ }^{22}$

\section{A ecoespiritualidade como dimensão profética das Religiões}

O Papa Francisco refere-se à espiritualidade como uma expressão humana integradora, de modo que "não está desligada do próprio corpo nem da natureza ou das realidades do mundo, mas vive com elas e nelas, em comunhão

\footnotetext{
${ }^{20}$ BOFF, L., Ecologia grito da terra, grito dos pobres, p. 288-289.

${ }^{21}$ MURAD, A., Ecologia, consciência planetária e bem viver, p. 17-61.

${ }^{22}$ FRANKY, C. H. D.; AGUIRRE, A. C., Espiritualidades, religiões e ecologia, p. 103-135.
} 
com tudo o que nos rodeia". ${ }^{23}$ A Laudato $S i$ ' traz em seu cerne a temática ecológica e perpassa metodologicamente a espiritualidade, ou seja, como transversalidade totalizante de seu conteúdo. Assim afirma Prates:

A espiritualidade como montante vinculado à reflexão teológica perpassa num formato de transversalidade a totalidade do conteúdo da encíclica Laudato Si', no arco dos seus seis capítulos. Laudato Si', mi' Signore, isto é, "Louvado sejas, meu Senhor" é uma expressão carregada de uma experiência espiritual feita por São Francisco de Assis - sec. XIII -, que inaugura, na tradição cristã ocidental, uma configuração da espiritualidade qualificada pela mediação da criação e de um estilo de vida sóbrio, austero, despojado, pobre e de valorização da pobreza. ${ }^{24}$

Partindo da fé cristã católica, o Papa Francisco sintoniza por meio da dimensão espiritual as diversas tradições religiosas, sejam elas, outras denominações cristãs ou propriamente tradições não cristãs, que com suas experiências religiosas mesmo que diferentes têm como ponto de encontro o desejo da vida oriunda de uma expressão mística de comunhão com o seu Criador através da criação.

A centralidade da vida como ponto de interseção das religiões é uma expressão de espiritualidade, porque nela está incutido o esforço em manter e potencializar toda forma de relacionamento e comunhão, pois, a origem da religião está na experiência de fé, no encontro com a divindade que conduz o ser humano à conquista da sua autorrealização, por isso, não está desconexa da realidade, existindo um todo a ser salvo. ${ }^{25}$

Tendo como pressuposto o panorama atual de pluralismo religioso, a espiritualidade não está apenas ligada a uma confissão religiosa, mas é também presença marcante na vida de pessoas que não pertencem a nenhuma denominação religiosa. A abertura ao sagrado deste grupo religioso ainda é visto de forma intolerante, pelo fato de sua espiritualidade ser interpretada como uma aspiração mística, conceito que ainda é considerado ligado a poderes ocultos ou práticas esotéricas, causando a falsa impressão de desconexão com a espiritualidade. $\mathrm{O}$ reconhecimento dessa mística como profunda expressão humana de espiritualidade torna inexistente a ruptura entre mística e espiritualidade, contudo, pode-se afirmar que há uma mística inter-religiosa que

\footnotetext{
${ }^{23}$ LS 216.

${ }^{24}$ PRATES, L. F., A espiritualidade como princípio transversal, p. 181-209.

${ }^{25}$ BOFF, L., Ecologia grito da terra, grito dos pobres, p. 293-294.
} 
"convida-nos a uma expressão mística de comunhão com o Criador através de sua criação", fundamento de uma ecologia profunda. ${ }^{26}$

As virtudes teologais, por serem hábitos que nascem da gratuidade de Deus e animam o agir moral humano, são os caminhos delineados por Leonardo Boff para a definição de ecoespiritualidade, ${ }^{27}$ assegurando que todo esforço do ser humano em cuidar e preservar o planeta está unido ao trabalho do Criador que sustenta e mantém em si todos os seres. Para Diaz Franky e Cáceres Aguirre, pensar a ecoespiritualidade é pensar na relacionalidade de Deus com sua Criação, porque parte da imagem de Deus como comunidade. Desta realidade presente em Deus, estabelece-se uma koinonia com os seres criados. ${ }^{28}$

A práxis transformadora contida na ecoespiritualidade, apresenta a dimensão profética do diálogo entre as religiões que superam suas diferenças, em favor de um clamor da natureza que se une ao grito dos excluídos e que comunica a presença do Criador na vida do ser humano e na realidade criada. Esta espiritualidade, por não estar alheia à realidade da natureza, implica para vida de cada ser vivente em uma luta ininterrupta e consciente do respeito ao outro e ao meio ambiente, ou seja, escolhas que têm como objeto a generosidade e a solidariedade rumo à solução da crise ecológica.

\section{A práxis ecológica a partir da conscientização, educação e o bem comum}

\subsection{Conscientização}

"Não há uma crise ambiental e outra social, mas uma única e complexa crise socioambiental", ${ }^{29}$ é esta a concepção ecológica do Papa Francisco que vislumbra uma ecologia integral, pois reconhece que tudo está interligado e a partir deste entendimento sugere como ação concreta para o enfrentamento da crise ecológica a conscientização de que "nossa origem comum, de uma recíproca pertença e de um futuro partilhado por todos" é condição fundamental para mudança no estilo de vida que ainda está calcado no consumismo obsessivo. ${ }^{30}$ Este é o caminho a ser trilhado para a superação dos problemas ambientais.

\footnotetext{
${ }^{26}$ FRANKY, C. H. D.; AGUIRRE, A. C., Espiritualidades, religiões e ecologia, p. 103-135.

${ }^{27}$ BOFF, L., Ecologia grito da terra, grito dos pobres, p. 305-306.

${ }^{28}$ FRANKY, C. H. D.; AGUIRRE, A. C., Espiritualidades, religiões e ecologia, p. 103-135.

${ }^{29}$ LS 139.

${ }^{30}$ LS 202-203.
} 
Esta exigência apresentada pelo Papa é acrescida de uma mudança no estilo de vida não apenas no âmbito individual, mas deve ser de forma coletiva, esta conversão ecológica, que requer criar um dinamismo de mudança duradoura, é também uma conversão comunitária. ${ }^{31}$

Dentro do propósito do diálogo inter-religioso, que visa tarefas comuns na solução dos problemas ambientais, é mais vantajoso "ser solidário" do que a tentativa de solução individual, portanto, em comunhão é possível reconstruir não só um projeto de vida particular, mas o sonho de toda a humanidade". ${ }^{32}$

Murad apresenta o processo de conscientização como articulação entre ecologia e a luta pela sociedade sustentável, daí brota a percepção humana que incide sobre a visão de si e de suas relações proporcionando um estilo de vida sustentável, onde esta percepção reflete-se como experiência religiosa que tem uma compreensão do ser humano correlato ao Sagrado. ${ }^{33} \mathrm{O}$ fato do ser humano se perceber como parte da criação leva-o a assumir responsabilidades perante o mundo em que vive, o que promove uma consciência planetária, que sem prescindir da coletividade "significa estar atento aos destinos do planeta conscientes dos problemas que o afetam, esta consciência atenta se encontra tanto presente a si mesma quanto na alteridade". ${ }^{34}$

O encantamento pela natureza é, para Leonardo Boff, parte no processo de conscientização que está orientado para um estilo de vida ecologicamente sustentável, fruto das experiências do cotidiano, permitindo o resgate das relações de interdependência entre todos os seres, mas foi perdida no decorrer do pensamento moderno detentor de um ideal de mundo e da natureza utilitarista. ${ }^{35}$ Estar encantado segundo o Papa Francisco é ter a "consciência amorosa de não estar separado das outras criaturas, é formar com os outros seres do universo uma estupenda comunhão universal". ${ }^{36}$

A consciência que parte de um encantamento do universo criado pelo Criador, cuja presença está na relação-comunhão entre todos os seres, no contexto de espiritualidade das tradições religiosas ganha consistência, devido ao fato da sua perspectiva ser de reconhecimento do Sagrado na Criação. Nesse sentido a espiritualidade passa a ser o exercício de consciência que aponta para

\footnotetext{
${ }^{31}$ LS 219.

${ }^{32}$ SUESS, P., Introdução à teologia da missão, p. 181.

${ }^{33}$ MURAD, A., Ecologia, consciência planetária e bem viver, p. 17-61.

${ }^{34}$ MURAD, A., Ecologia, consciência planetária e bem viver, p. 17-61.

${ }^{35}$ BOFF, L., Ecologia grito da terra, grito dos pobres, p. 304.

${ }^{36}$ LS 220.
} 
a convivência do ser humano com a criação, superando a decadência humanoecológica. ${ }^{37}$

\subsection{Educação}

Segundo o Papa Francisco, a educação ambiental incide diretamente no comportamento humano e o seu pleno exercício é capaz de restituir o sentimento de dignidade, mas para isso a educação ambiental deve ir além de uma conscientização propriamente científica, mas dispor dos distintos níveis de equilíbrio ecológico que perpassa pelo conhecimento de si, que por autoobservação percebe um conjunto de relações que abrange o outro, a natureza e o Criador. Esse desenvolvimento educacional ambiental possibilita um processo mistagógico onde estabelece uma ética ecológica no sentido mais profundo. $^{38}$ Francisco:

Sanchez afirma que é este o papel das religiões na visão do Papa

Cada tradição religiosa tem seus valores e inspirações que permitem um novo olhar e uma nova relação com a natureza, e podem tirar de seu tesouro religioso elementos para que as pessoas venham a combater o desrespeito à natureza e cultivar novos hábitos com vistas ao cuidado da casa comum. ${ }^{39}$

Faz-se necessário acrescentar que o processo educacional, a partir de uma ótica crítica e integral, tem como estrutura fundante os conceitos de conhecimento genérico, genético e genuíno, sendo o primeiro vinculado à proposta de crítica reflexiva em favor das necessidades humanas e conduzindo ao bem comum, enquanto o conceito de conhecimento genético reporta-se à formação humana herdada de gerações anteriores que visa responder às necessidades de seu contexto cultural, promovendo práticas afetivas de alteridade. Sobre a educação genuína, enfim, sabe-se que traz em seu cerne o desenvolvimento humano numa perspectiva integralista que fortalece a consciência de solidariedade e cooperação. $\mathrm{O}$ fato de ser um conhecimento integral, estimula a dimensão espiritual, capacita a pessoa a fazer atividades cotidianas com sentido no sagrado. O processo educacional como descrito

\footnotetext{
${ }^{37}$ PRATES, L. F., A espiritualidade como princípio transversal, p. 181-209.

${ }^{38}$ LS 210-211.

${ }^{39}$ SANCHEZ, W. L., O diálogo inter-religioso: fontes e método, p. 157-178.
} 
acima com o entrelaçamento de cada conceito de conhecimento, pode realizar na humanidade uma aliança com o meio ambiente sem descartar o transcendente, essa proposta de educação faz parte do protagonismo das religiões. ${ }^{40}$

É por meio do desenvolvimento educacional ambiental que vislumbramse novos horizontes que não se limitam apenas ao social, ao político, ao cultural, mas remetem a uma perspectiva integral que contempla também a espiritualidade, aprimorando, em cada crente, a compreensão de sua relação de alteridade com a natureza, como forma de edificação de construção de uma vida melhor individual e comunitária, avistando não só o presente mas as futuras gerações.

\subsection{O bem comum}

A Crise ecológica instalada nos dias atuais, produz um sistema de degradação ambiental atrelado à degradação humana e ao mesmo tempo proporciona para as tradições religiosas uma atuação profética que, por meio da espiritualidade ecológica, conduz cada crente a uma consciência da responsabilidade comum. O Papa Francisco, ao mencionar essa responsabilidade, entende que a família e o Estado estão implicados na defesa do bem comum e que esta compreensão tem alcance intergeracional, afinal uma ecologia integral envolve a solidariedade entre as gerações. ${ }^{41}$

Leonardo Boff ao desenvolver sua reflexão sobre a ética ecológica, a entende como desenvolvimento de um sentido que freia os desejos de opressão e exploradores no interior humano e concomitantemente potencializa o sentido de solidariedade intergeracional, e para tal empreitada é necessária uma mística, uma espiritualidade que funda um novo acordo com todos os seres restabelecendo a re-ligação, questão que foi perdida através da cultura de ruptura com a natureza construída na modernidade. ${ }^{42}$

O fato da espiritualidade não estar ligada a uma confissão religiosa, mas vinculada a um processo vital de sentido de existência, presente nos princípios de sabedoria das religiões ancestrais, sem deixar de levar em consideração a sociedade hodierna mergulhada num universo plural religioso advindo de um contexto globalizado, mostra a necessidade de busca da unidade de toda a

\footnotetext{
${ }^{40}$ VALlinOTO, M. J. S.; NIÑO, N. I. P.; CLAVIJO, G. R. M., Educar para o bem viver à luz da fé, p. 179-188.

${ }^{41}$ LS 157-159.

${ }^{42}$ BOFF, L., Ecologia grito da terra, grito dos pobres, p. 23-24.
} 
família humana - crentes e não crentes - por meio da consciência do bem comum que irrompa as gerações, de modo que nossos ancestrais primitivos que nos proporcionaram desfrutar de um meio ambiente cheio de vida inspirem na geração atual a generosidade de entregar às gerações futuras uma natureza rica, cheia de vida e sem as marcas da degradação. ${ }^{43}$

\section{Conclusão}

Numa sociedade marcada pelo consumismo, que produz uma falsa ideia de que é preciso ter para ser feliz, o Papa Francisco lança o desafio urgente para se despertar a consciência ecológica, ${ }^{44}$ portanto, este desafio é dirigido a todos e isto inclui as religiões com o papel preponderante de re-ligar a natureza, o ser humano e o Criador.

No íntimo desse apelo de combate ao projeto de destruição da natureza, emerge, em torno de uma causa comum, o processo dialogal entre as religiões de assumirem seu papel missionário de acolhimento do movimento ecológico contemporâneo, solidifica-se com o diálogo entre as organizações socioambientais da sociedade civil, o Estado e a solidariedade de todos os povos, a partir desta perspectiva dialogal, que faz as pessoas se comprometerem na defesa da integração entre o ser humano e a criação.

Esta reconciliação entre homem e natureza requer uma "espiritualidade ecológica que nasce das convicções de fé" 45 que diante de uma crise ecológica exige uma conversão ecológica, ou seja, uma atitude que vem do interior, resultando na harmonia da condição original, que foi perdida num processo cultural que privilegia, no seu ideal imaginário, a ruptura com a natureza.

Tendo como base um projeto de convivência respeitosa entre tudo que está interligado, Vilas Boas, na busca de uma compreensão mais holística que comporta a pluralidade cultural e teológica, propõe o hipodigma ${ }^{46}$ da ética planetária como processo de metanóia no ser humano que o convida a uma ética

\footnotetext{
${ }^{43}$ FRANKY, C. H. D.; AGUIRRE, A. C., Espiritualidades, religiões e ecologia, p. 103-135.

${ }^{44}$ LS 13.

${ }^{45}$ LS 216.

${ }^{46}$ Hipodigma da ética planetária: esta é uma categoria da biologia sistemática, e de modo geral diz respeito às características comuns entre determinadas espécies, utilizadas para a taxonomia da classificação biológica. Hipodigma diz respeito então às características em comum entre o ser humano, a baleia e os macacos, que os classifica como mamíferos. Pensar hipodigmaticamente é procurar elementos comum. VILAS BOAS, A., Paradigma de uma ética planetária, p. 211- 231.
} 
do cuidado entre as espécies e tem como ponto de partida suas características comuns.

Deve-se acrescentar que a conversão ecológica precisa ser estabelecida numa sociedade pautada pela inovação do conhecimento como base estruturante do seu constante movimento de transformação. É neste contexto que a espiritualidade deve encarnar-se. Para isso as religiões podem contribuir de maneira inovadora a partir de um conhecimento silencioso, que é uma característica do apreço pela realidade, porém com a capacidade de estar desapegado, favorecendo uma condição de plena liberdade dos condicionamentos habituais da realidade, é nesse sentido que a pluralidade religiosa pode efetivar a mudança de paradigma. ${ }^{47}$

O Papa Francisco engloba como processo de conversão ecológica a sobriedade, que é um ensinamento presente nas distintas tradições religiosas. Ele afirma que este modo de viver contém uma práxis libertadora porque "é possível necessitar de pouco para viver muito, pois a felicidade exige saber limitar algumas necessidades que nos entorpecem". ${ }^{48}$ Este processo de amadurecimento espiritual produz um estado de paz interior, pois o ser humano enamorado da beleza da Criação reflete-se em um equilibrado estilo de vida ordenado pelo cuidado da ecologia e o bem comum. ${ }^{49}$

Essa iniciativa movida pela perspectiva da espiritualidade, fundamento inerente das religiões, favorece a formação de uma reta consciência ambiental, ajudando a população a ser mais solidária principalmente com os mais pobres que são afetados diretamente pela degradação ambiental. Este desafio constituinte da caminhada rumo ao projeto do Reino de Deus não pode deixar de inspirar-se no movimento de denúncia própria das tradições proféticas que tiveram papel decisivo nas religiões. Hoje, a práxis religiosa tem como meta, uma experiência de fé que inclui a responsabilidade da casa comum, possibilitando uma ecologia integrada que comporta as dimensões ambientais e sociais pois, tudo está interligado; a vida humana está ligada à vida da natureza e à espiritualidade como fruto de uma religião do amor que estabelece a íntima relação entre os seres humanos e toda a Criação.

\footnotetext{
${ }^{47}$ PANASIEWICZ, R., O paradigma pós-religional desafia a teologia do pluralismo religioso, p. 20-33.

${ }^{48}$ LS 223.

${ }^{49} \operatorname{LS} 225$.
} 


\section{Referências bibliográficas}

BOFF, L. Ecologia grito da terra, grito dos pobres. 2a ed. São Paulo: Ática, 1996. CELAM. Documento de Aparecida. Texto conclusivo da V ConferênciaGeral do Episcopado Latino-Americano e do Caribe. São Paulo: Paulus / Paulinas; Brasília: CNBB, 2008.

CONCÍLIO VATICANO II. Decreto Ad Gentes sobre a atividade missionário. In: VIER, F. (Org.). Compêndio do Vaticano II. Constituições, decretos e declarações. 19a ed. Petrópolis: Vozes, 1987. p. 349-399.

FRANKY, C. H. D.; AGUIRRE, A. C. Espiritualidades, religiões e ecologia. In: MURAD, A. (Org.). Ecoteologia: um mosaico. São Paulo: Paulus, 2016. p. 103-135.

MURAD, A. Ecologia, consciência planetária e bem viver. In: MURAD, A. (Org.). Ecoteologia: um mosaico. São Paulo: Paulus. 2016. p. 17-61.

PANASIEWICZ, R. O paradigma pós-religional desafia a teologia do pluralismo religioso. In: RIBEIRO, C. O. (Org.). Espiritualidades contemporâneas, pluralidade religiosa e diálogo. São Paulo: Fonte Editorial, 2016. p. 15-37.

FRANCISCO, PP. Evangelli Gaudium - sobre o anúncio do Evangelho no mundo atual. São Paulo: Loyola, 2013.

FRANCISCO, PP. Laudato Si' - sobre o cuidado da casa comum. São Paulo: Edições Loyola, 2015.

PRATES, L. F. A espiritualidade como princípio transversal. In: PASSOS, J. D. (Org.). Diálogos no interior da casa comum: recepções interdisciplinares sobre a encíclica Laudato Si'. São Paulo: Paulus, 2016. p. 181-210.

SANCHEZ, W. L. O diálogo inter-religioso: fontes e método. In: PASSOS, J. D. (Org.). Diálogos no interior da casa comum: recepções interdisciplinares sobre a encíclica Laudato Si'. São Paulo: Paulus, 2016. p. 157-178.

VALLINOTO, M. J. S.; NIÑO, N. I. P.; CLAVIJO, G. R. M. Educar para o bem viver à luz da fé. In: MURAD, A. (Org.). Ecoteologia: um mosaico. São Paulo: Paulus, 2016. p. 167-204.

VILAS BOAS, A. Paradigma de uma ética planetária. Um olhar a partir da ecologia da vida cotidiana na Laudato Si'. In: PASSOS, J. D. (Org.). Diálogos 
no interior da casa comum: recepções interdisciplinares sobre a encíclica Laudato Si. São Paulo: Paulus, 2016. p. 211-231.

SUESS, P. Introdução à teologia da missão: convocar e enviar: servos e testemunhas do Reino. Rio de Janeiro: Vozes, 2009.

\section{Edevaldo Rocha}

Mestrando em Teologia pela Pontifícia Universidade Católica de São Paulo São Paulo / SP - Brasil E-mail: ercos72@yahoo.com.br

Recebido em: $10 / 12 / 18$ Aprovado em: 20/12/18 